\title{
Artigo
}

\section{A indústria naval civil e militar na China e na Coreia do Sul: análise histórica e tendências atuais (1960-2015)}

\author{
The civil and military shipbuilding industry in China and South Korea: historical \\ analysis and current trends (1960-2015)
}

DOI: 10.5752/P.1809-6182.2016v13.n2.p68

Raul Cavedon Nunes ${ }^{1}$

\section{RESUMO}

Recebido em: 04 de abril de 2016 Aprovado em: 07 de julho de 2016

Este trabalho tem como objetivo realizar um estudo inicial exploratório acerca da formação do complexo militar-industrial chinês e sul-coreano no que tange à indústria naval. Em particular, trata da relação entre o Estado e as empresas, mediada pelos mecanismos e os sujeitos que realizam a gestão administrativa, política e econômica do país. Trabalha-se com a hipótese de que China e Coreia do Sul criaram, cada um a seu modo, um sistema de retroalimentação entre a induistria naval civil e militar para formar cadeias produtivas e de valor com ramos industriais relacionados. Em ambos os casos, o Estado teve um papel central na alavancagem do complexo militar-industrial, principalmente em relação ao financiamento, à abertura de mercados, ao fornecimento de matérias-primas, construção de infraestrutura e na formação de parcerias internacionais. Na China, este sistema utilizou os diversos niveis administrativos do Estado (provincias e municipios), joint-ventures e conglomerados estatais (principalmente a China State Shipbuilding Corporation e a China Shipbuilding Industry Corporation). Na Coreia do Sul, os Chaebols como a Hyundai, a Daewoo e a Samsung administram uma série de empresas atuando desde a induistria de defesa até a de bens de consumo, particularmente ligadas a produtos eletrônicos.

Palavras-chave: China. Coreia do Sul. Defesa; Induistria Naval. Complexo Militar Industrial.

\section{ABSTRACT}

This article aims to conduct an initial exploratory study on the formation of the Chinese and South Korean military-industrial complex regarding the shipbuilding industry. In particular, it analyses the relationship between the State and the private sector, mediated by the mechanisms and the actors who perform the administrative, political and economic managment. The hypothesis is that China and South Korea have created, each in its own way, a sinergy system between the civilian and the military shipbuilding to form productive and value chains with related industries. In both cases, the State played a central role in leveraging the military-industrial complex, especially in relation to financing, opening of new markets, supply of raw materials, infrastructure and the formation of international partnerships. In China, this system used the various administrative levels of the State (provinces and municipalities), joint ventures and state-owned conglomerates (especially China State Shipbuilding Corporation and China Shipbuilding Industry Corporation). In South Korea, the Chaebols like Hyundai, Daewoo and Samsung manage companies operating in the defense industry and in the consumer goods market, particularly related to electronic products.

Keywords: China. South Korea; Naval Defense. Shipbuilding Industry. Military Industrial Complex.

1. Mestrando do Programa de Pós-Graduação em Estudos Estratégicos Internacionais da Universidade Federal do Rio Grande do Sul (PPGEEI-UFRGS). Pesquisador Assistente do Núcleo Brasileiro de Estratégia e Relaçóes Internacionais (NERINT-UFRGS) e pesquisador do Instituto Sul-Americano de Pesquisa e Estratégia (ISAPE). orcid. org/0000-0003-1301-5976 


\section{Introdução}

Este trabalho tem como objetivo analisar, a partir de uma perspectiva histórica e processual, como China e Coreia do Sul alcançaram o patamar de maiores construtores navais do mundo a partir do final do século XX. A Tabela 1 abaixo demonstra o aumento vertiginoso da indústria naval desses países nas últimas décadas, chegando a responder, juntamente com o Japão, a mais de $70 \%$ do market share do setor a partir de 2007.

Especificamente, o artigo estuda os Arranjos Institucionais Híbridos ${ }^{2}$ construídos entre Estado, setor privado e instituiçôes de pesquisa, e qual foi o papel das parcerias internacionais neste processo. Trabalha-se com a hipótese de que China e Coreia do Sul criaram, cada um a seu modo, um sistema de retroalimentação entre a indústria naval civil e militar para formar cadeias produtivas e de valor com ramos industriais relacionados. Em ambos os casos, o Estado teve um papel central na alavancagem do complexo militar-industrial, principalmente em relação ao financiamento, à abertura de mercados, ao fornecimento de matérias-primas, construção de infraestrutura e na formação de parcerias internacionais.

$\mathrm{Na}$ China, a indústria naval, assim como outros ramos da indústria de defesa e civil, possuem um modelo híbrido de administração e gestão de empresas, particularmente ligadas aos diferentes níveis administrativos do Estado chinês:

- estaleiros administrados por províncias (equivalentes aos estados da federação no Bra-

2. Arranjos Institucionais Híbridos - $\mathrm{O}$ arranjo institucional híbrido é um conjunto de regras, mecanismos e processos que definem a forma particular como se coordenam atores e interesses na implementaçáo de uma política pública específica (GOMIDE; PIRES, 2014, p. 19-20; FIANI, 2014, p. 62). O termo híbrido designa um arranjo institucional formado por atores estatais, privados e do setor de serviços articulados por um Centro Estratégico. Os arranjos institucionais híbridos podem assumir diversas formas, como joint ventures, alianças estratégicas, cadeias de fornecedores, franquias, parcerias público-privadas (PPPs), parques tecnológicos, entre outros. sil), (2) estaleiros pertencentes a conglomerados ou companhias estatais;

- joint ventures com empresas do exterior;

- estaleiros pertencentes à Marinha da China (PLAN, sigla em inglês); e

estaleiros administrados por municípios chineses (MEDEIROS et al. 2005, p. 116). Na Coreia do Sul, os Chaebols ${ }^{3}$ como a Hyundai, a Daewoo e a Samsung administram uma série de empresas atuando desde a indústria de defesa até a de bens de consumo, particularmente ligadas a produtos eletrônicos. A China ultrapassou o market share da Coreia do Sul na década de 2000, mas os sul-coreanos ainda detêm as maiores empresas do setor. O tamanho dos navios construídos pela Coreia do Sul é maior, com uma média de 28.000 toneladas por navio, enquanto a média dos navios chineses é de 16.800 toneladas (WON, 2010, p. 21-22). Entretanto, a China produz um número maior de embarcações de menor porte, o que explica a menor tonelagem média.

A indústria de construção naval desses países não ficou restrita ao mercado civil, mas também passou a competir na produção de submarinos e vasos de guerra de superfície. Isto pode ser verificado pela sua configuração da força naval, equiparando e até superando algumas potências tradicionais (Tabela 2).

A indústria naval tem como característica a possibilidade de criar sinergias entre os setores civil e militar da economia, particularmente no que tange aos componentes ${ }^{4}$ produzidos para as

3. Chaebol (Coreia do Sul) - "grandes conglomerados de empresas administradas por gerentes profissionais, mas cuja propriedade e administração financeira é de caráter familiar, representada pelo Chongsu (o administrador-geral do Chaebol, um representante da família proprietária)" (MURILLO; SUNG, 2013, p. 3).

4. Uma breve análise das partes constituintes de um navio demonstra a série de cadeias produtivas e spin-off para a economia civil que essa indústria pode alavancar: (1) Estrutura (casco e superestrutura), (2) Máquinas Principais (propulsão, transmissão e sistemas de óleo combustível e óleo lubrificante), (3) Máquinas Auxiliares (bombas, válvulas, redes 
Tabela 1 - Número de Embarcações Encomendadas (2002-2015)

\begin{tabular}{c|c|c|c|c|c}
\hline Ano & Mundo & China $(\mathbf{A})$ & Coreia do Sul $(\mathbf{B})$ & Japáo $(\mathbf{C})$ & (A+B+C)/mundo (\%) \\
\hline 2002 & 2.437 & 348 & 480 & 551 & 57 \\
\hline 2003 & 2.497 & 357 & 488 & 645 & 60 \\
\hline 2004 & 3.484 & 563 & 790 & 970 & 67 \\
\hline 2005 & 4.483 & 862 & 1.017 & 1.123 & 67 \\
\hline 2006 & 5.773 & 1.290 & 1.128 & 1.303 & 64 \\
\hline 2007 & 7.788 & 2.243 & 1.457 & 1.553 & 67 \\
\hline 2008 & 10.721 & 3.709 & 2.206 & 1.828 & 72 \\
\hline 2009 & 11.071 & 4.102 & 2.308 & 1.910 & 75 \\
\hline 2010 & 9.164 & 3.641 & 1.847 & 1.539 & 77 \\
\hline 2011 & 8.198 & 3.511 & 1.556 & 1.326 & 78 \\
\hline 2012 & 6.308 & 2.647 & 1.161 & 983 & 76 \\
\hline $2013^{*}$ & 5.994 & 2.161 & 890 & 825 & 87,4 \\
\hline $2014^{*}$ & 6.148 & 2.454 & 865 & 941 & 88,4 \\
\hline $2015^{* *}$ & 8.174 & 2.397 & 840 & 918 & 51 \\
\hline
\end{tabular}

Fonte: Adaptado de (DORES; LAGE; PROCESSI, 2012, p. 289).

* Dados de 2013 e 2014 obtidos no relatório da Associaçáo Japonesa de Construçáo Naval (SHIPBUILDING..., 2015).

** Dados de 2015 obtidos no relatório do SINAVAL do primeiro semestre de 2015.

Tabela 2 - Submarinos, Meios de Superfície e Navios Anfíbios (2016)

\begin{tabular}{c|c|c|c|c|c|c|c|c|c|c}
\hline & ING & FRA & ITA & EUA & RUS & JAP & COR & CHI & IND & BRA \\
\hline SUB & 10 & 10 & 6 & 71 & 63 & 18 & 23 & 61 & 14 & 5 \\
\hline SUP & 19 & 23 & 19 & 98 & $35^{*}$ & 47 & 59 & $74^{* *}$ & $28^{* * *}$ & 14 \\
\hline ANF & 3 & 3 & 4 & 30 & 19 & 3 & 2 & 3 & 1 & 1 \\
\hline & & & & & & & & & & \\
\hline
\end{tabular}

Fonte: (INTERNATIONAL INSTITUTE FOR STRATEGIC STUDIES, 2016).

* + 46 corvetas capazes de lançar mísseis anti-navio e/ou antiaéreos.

** +115 corvetas e navios-patrulha capazes de lançar mísseis anti-navio e/ou antiaéreos.

*** + 24 corvetas e navios-patrulha capazes de lançar mísseis anti-navio e/ou antiaéreos.

embarcaçôes, na expertise acumulada pela mão de obra e nos sistemas de modelagem virtual, design, engenharia, etc. As mesmas técnicas e conceitos básicos utilizados na produção de navios comerciais mais eficientes em termos de combustível, como graneleiros, também são utilizados pelos de água doce e água salgada, refrigeração e sistema de governo), (4) Eletricidade (geração, distribuição, iluminação), (5) Comunicaçóes (interiores e exteriores, navegação), (6) Acessórios do Casco e Convés (controle de avarias, manipulação de pesos), (7) Acabamento (compartimentos e estaçóes de trabalho), (8) Sistemas de Combate (armamento, sensores, centro de controle, munição, lançadores, sistemas de bloqueio e despistamento) (AIAB, 2011 apud AGÊNCIA BRASILEIRA DE DESENVOLVIMENTO INDUSTRIAL 2013, p. 10). estaleiros para aumentar o alcance e a velocidade dos combatentes de superfície. Além disso, a técnica de construção em módulo, os cascos de alumínio, a produção de turbinas ${ }^{5}$ e até as máquinas fresadoras têm uso dual (COLLINS, 2010, p. 3). Trata-se, portanto, de uma área capaz de integrar setores produtivos anteriormente desconexos desde a indústria de base, matérias-primas, produção 5. Turbinas Aeroderivadas - Segundo Oliveira (2012), "as turbinas aeroderivadas são até hoje o motor de uso contínuo mais poderoso já criado pelo homem. Desde os maiores avióes, navios de grande porte (petroleiros, cargueiros, novos porta-avióes), incluindo uma grande variedade de veículos (blindados, lanchas, hovercrafts), grandes unidades industriais, petroquímicas e de mineração". 
de bens de capital, e de bens de alto valor agregado como a microeletrônica, turbinas e supercomputadores.

Nesse sentido, o esforço de pesquisa deste trabalho foi dividido em três partes: a primeira trata da indústria naval civil e militar chinesa a partir de sua evolução histórica, além do papel do Estado e das Relaçôes Internacionais neste processo. Em segundo lugar, realiza-se o mesmo esforço analisando a Coreia do Sul. Por fim, tiram-se conclusóes acerca dos estudos de caso e são apontadas algumas tendências atuais da indústria naval, assim como os desafios políticos, econômicos e estratégicos a serem enfrentados pelos dois países nos próximos anos.

\section{A indústria naval civil e militar na República Popular da China}

A primeira organização militar responsável pela defesa naval na China após a Revolução de 1949 foi a East China People's Navy (ECPN) ${ }^{6}$, criada em maio de 1949 e subordinada em janeiro de 1950 ao Comando Militar do Leste East China Military Command ( ECMC), com sede em Xangai (COLE, 2009, p. 321). O ECPN era responsável pela defesa costeira contra as forças de Chiang Kai-shek, entâo apoiadas pelos EUA, por enfrentar o bloqueio marítimo realizado pelas marinhas inimigas, e também por ajudar na reconstrução econômica do país (COLE, 2009, p. 321). Além disso, tinha a incumbência de garantir a segurança dos rios interiores da China, particularmente do Rio Yangtzé (Rio Azul). Assim, para qualificar os oficiais responsáveis pela organização militar, Liu

6. O primeiro comandante da Marinha chinesa foi Liu Huaqing, que ainda em agosto de 1949 havia estabelecido uma Universidade voltada para a formação de oficiais navais em Nanjing, e iniciou a organização da infraestrutura logística e de manutenção necessários para as novas esquadras.
Huaqing, o primeiro comandante da ECPN, estabeleceu em agosto de 1949 um centro de formação para comandantes da Marinha em Nanquim, construindo as bases da fundação da Marinha do Exército de Libertação Popular (PLAN), o que ocorreria em maio de 1950 (COLE, 2009, p. 321).

Entretanto, os recursos financeiros e tecnológicos para a construção dos vasos de guerra e da infraestrutura necessária para a manutençâo e logística dos navios veio em grande parte da parceria estratégica com a União Soviética (URSS). Em setembro de 1949, Liu Huaqing visitou Moscou em busca de financiamento e auxílio na construção de infraestrutura portuária, estaleiros, compra e manutenção de navios (COLE, 2014, p. 50; 2009, p. 321). Três meses depois, em dezembro de 1949, Mao Tsé-Tung deixou pela primeira vez o país, viajando até Moscou para negociar com Stalin. O resultado foi a assinatura do Tratado Sino-Soviético de Aliança e Assistência Mútua, no qual havia uma promessa de apoio mútuo em caso de ataque pelo Japão e o adiantamento por parte da URSS de 300 milhóes de dólares em créditos à China (ROBERTS, 2012, p. 284).

Em relação à modernização naval, houve tentativas de aquisição de navios estrangeiros como dois cruzadores da Grã-Bretanha, e de outros navios por intermédio de Hong Kong. Entretanto, com o desencadeamento da Guerra da Coreia (1950-1953) ${ }^{7}$ , a URSS passou a ser o único fornecedor de meios navais à China: foram comprados quatro submarinos, dois destróiers, dez corvetas e um grande número de navios-patrulha. Mao Zedong também contou com a recepção de militares soviéticos no país (cerca de 500 em 1950 e de 1.500 a 2.000 em 1953) para o treinamento de oficiais chineses (COLE, 2009, p. 323). Além disso, a RPC capturou das forças nacionalistas quarenta navios de de-

7. Segundo Roberts (2012, p. 285), a Guerra da Coreia vitimara mais de 700 mil chineses e trouxe um alto endividamento do país com a União Soviética derivada da compra de armamentos. 
sembarque (landing craft), navios-patrulha fluviais, navios caça-minas e embarcações de apoio a estaleiros, muitos desses produzidos pelos EUA (COLE, 2009, p. 323).

A infraestrutura portuária e de estaleiros para a construção de novos vasos de guerra submarinos e de superfície foi ampliada com a retomada da regiáo de Dalian, Lushun e Huludao, localizados no Mar Amarelo, próximos à Coreia (COLLINS ; GRUBB, 2009, p. 346). A partir dos acordos com a URSS, a China obteve recursos para construir, por exemplo, quatro fragatas da Classe Chengdu, baseadas na Classe Riga soviética (COLLINS; GRUBB, 2009, p. 347). Além da construção de barcos armados com torpedos, navios caça-minas e vasos de guerra auxiliares, os estaleiros chineses voltaram a produzir embarcaçóes para a área civil, como cargueiros, navios de pesca e rebocadores, ainda que em um segundo plano (COLLINS; GRUBB, 2009, p. 347).

Visando atingir seus objetivos estratégicos e operacionais, o país almejava a produção de um grande número de submarinos e de vasos de guerra de baixa tonelagem para a proteção do litoral. Além disso, demandava a aquisiçấo de meios de projeção de poder em direção às ilhas circundantes $^{8}$, ou seja, de navios anfíbios, de transporte e também de aviação ${ }^{9}$ para a cobertura aérea para suas frotas (COLE, 2009, p. 323). Contudo, devido às recorrentes intimidaçóes e chantagens nucleares estadunidenses na década de 1950, os recursos para tais modernizaçóes seriam deslocados para o desenvolvimento de capacidades nucleares

8. Pode-se citar alguns exemplos: (1) o bem sucedido assalto anfíbio chinês às Ilhas Dachen em 1954, enquanto simultaneamente a PLAN defendia seus portos e navios mercantes frente às incursôes do Kuomitang; e (2) os bombardeios às ilhas Quemoy e Matsu, ambas em posse de Chiang Kai-Shek (COLE, 2009, p. 325-326).

9. A Força Aérea da Marinha chinesa foi fundada em 1952, sendo composta inicialmente por caças MiG-15, bombardeiros Il-28 e Tu-2 (COLE, 2009, p. 326). próprias, principalmente a partir da Segunda Crise dos Estreitos em 1958 (MARTINS; MAGNO, 2013, p. 109). Ademais, a ruptura com a URSS na década de 1960, e a consequente saída dos técnicos soviéticos do país fez-se sentir também na indústria naval civil, que retraiu sua capacidade produtiva por não ter mais acesso a subcomponentes e a tecnologias produzidos fora do país (COLLINS;GRUBB, 2009, p. 347).

Além da ruptura com a URSS, a guerra contra a Índia (1962), somada às liçôes da Guerra da Coreia, fortaleceu a percepçáo da necessidade da modernização das capacidades das Forças Armadas do país (COLE, 2014, p. 13). Na indústria naval, isso levou à criação do Sexto Ministério de Construção de Máquinas (Sixth Ministry of Machine Building) em 1963, com o objetivo de centralizar o controle sobre as atividades da indústria naval no país (COLLINS; GRUBB, 2009, p. 347). Entretanto, a ênfase orçamentária nas armas nucleares, a interiorização da indústria pesada (a "terceira linha" de defesa de Mao Zedong) e a crise econômica resultante do Grande Salto Adiante (1958-1961) ${ }^{10} \mathrm{e}$ da Revolução Cultural (1966-1976) ${ }^{11}$ contribuíram para a falta de recursos para a modernização da Marinha e da indústria naval ${ }^{12}$ (COLE, 2014, p. 11).

10. Grande Salto Adiante - Programa de intensificação dos investimentos industriais no campo, particularmente na produção de ferro e aço. Segundo Dumas (2014, p. 52), "em termos macroeconômicos, o nível de investimentos cresceu substancialmente como percentual do PIB, passando de $15 \%$ em 1955 para mais de 30\% em 1960". O objetivo, segundo o autor, era "transferir alimentos da zona rural a um baixo custo para a zona urbana, como forma de manter baixos os salários da força de trabalho dela e a lucratividade das suas empresas estatais ou coletivas" (DUMAS, 2014, p. 53). O resultado, entretanto, foi uma diminuiçáo da produtividade no campo e uma escassez de alimentos que resultou em 25 a 30 milhóes de mortos (DUMAS, 2014, p. 56).

11. Revoluçáo Cultural - Movimento político-social lançado por Mao Tsé-Tung com o objetivo de romper com os antigos valores chineses (ideias, culturas, costumes e hábitos) por meio da utilização dos "guardas vermelhos", da reforma educacional no setor urbano e a utilizaçáo de jovens da cidade como professores na zona rural (DUMAS, 2014, p. 70-71).

12. Segundo Dumas (2014, p. 57-58), nesse período "as consideraçóes quanto à defesa militar sobrepuseram as consider- 
Em relação à modernização militar, a China até a década de 1970 havia priorizado os submarinos capazes de lançar mísseis nucleares e vasos de baixa tonelagem para a defesa do litoral. Daí a construção sob licença dos primeiros submarinos nucleares de ataque e de cerca de 60 submarinos convencionais da Classe Romeo, Type 033 (COLE, 2014, p. 13, 53). O esforço realizado para o domínio das tecnologias para lançamento de mísseis nucleares também daria à China a possibilidade de avançar no desenvolvimento de mísseis cruzadores convencionais, lançados tanto de submarinos quanto de vasos de superfície.

\section{A aproximaçáo com os EUA e as grandes modernizaçóes de Deng Xiaoping}

A aproximação com os EUA, que estavam em um impasse político, econômico e militar na Guerra do Vietnă, foi acompanhada pelo início do reatamento das relaçôes diplomáticas chinesas com o Japão - iniciado em 1971 e consolidado em 1973 -, o que traria grandes benefícios econômicos para a China nas décadas seguintes. Tal postura levou à entrada da China no Conselho de Segurança da Organização das Naçóes Unidas (ONU) em 1971 no lugar de Taiwan, e à adesão do país ao Banco Mundial e ao Fundo Monetário Internacional (FMI). A morte de Mao Zedong em 1976 ocorreu simultaneamente à ascensão política de Deng Xiaoping, que já havia ocupado o cargo de secretário-geral do PCC na década de 1960, chegaria à presidência do país em 1978 e ao Comando Militar Central em

ações econômicas e as vantagens comparativas”. Este trabalho concorda com o autor somente de forma parcial. Ainda que a priorizaçáo dos investimentos na indústria pesada e a ênfase nas armas nucleares tenham retirado recursos passíveis de serem empregados em outras áreas da economia chinesa (como a indústria naval), não se pode generalizar uma relação de oposição entre defesa militar e consideraçóes econômicas. O próprio modelo de desenvolvimento chinês adotado a partir das décadas de 1980 e 1990 foi construído justamente para conciliar Modernização Militar e Desenvolvimento Econômico, sinergia que também ocorreu na história dos EUA e da Coreia do Sul, por exemplo, com resultados positivos.
1981 (COLE, 2009, p. 329). Deng Xiaoping, em sua carreira política, teve como objetivo realizar reformas econômicas para inserir a China de forma competitiva na economia internacional.

O novo grupo no poder deu início ao plano econômico denominado "quatro modernizações", visando impulsionar a economia nas seguintes áreas: indústria, agricultura, ciência e tecnologia, e segurança (SILVA, 2015). Além disso, o Estado chinês levou as empresas de defesa a investir também na indústria civil e expandir sua vendas de produtos de defesa para o exterior, já que o orçamento do Estado chinês nesse setor, por si só, não traria a demanda necessária para ganhos de escala (MEDEIROS et al. 2005, p. 4-5). Neste quesito, Medeiros et al (2005, p. 6) destaca a indústria naval e a indústria eletrônica como os setores cujas empresas melhor obtiveram uma sinergia entre a economia civil e a indústria de defesa.

Além disso, foi adotado um novo regime comercial e de atração de Investimento Estrangeiro Direto (IED) visando o aumento das exportações: as Zonas Econômicas Especiais (ZEE). Nas ZEEs foram estabelecidas regras especiais para a promoção do comércio exterior, subsídios fiscais, diminuição dos impostos sobre importação de insumos, etc. Dentre as principais ZEEs há a Shenzhen, próxima a Hong Kong, a Zhuhai, perto de Macau, a Shantou, próxima à província de Guangdong, e a ZEE de Xiamen, instalada perto de Taiwan (CUNHA, 2012, p. 55). Assim, a partir dos anos 1980 houve um aumento constante de investimentos externos no país ${ }^{13}$ : passou de uma média de US $\$ 5$ bilhóes por ano para US\$ 40 bilhôes/ano na década de

13. A conta capital e financeira chinesa permaneceu superavitária devido ao grande influxo de capitais sob forma de Investimento Externo Direto (IED), e também pelo "influxo de outras modelidades de capitais - que a despeito dos controles de capitais, passaram a especular cada vez mais a favor de um yuan renminbi (RMB) forte" (CUNHA, 2012, p. 42). A força da economia chinesa the permitiu impulsionar vultuosas iniciativas no Sistema Internacional, como o Banco dos BRICS e o Banco Asiático de Investimento em Infraestrutura (AIIB). 
Figura 1 - Mudanças na Estrutura Organizacional da Indústria de Defesa da China

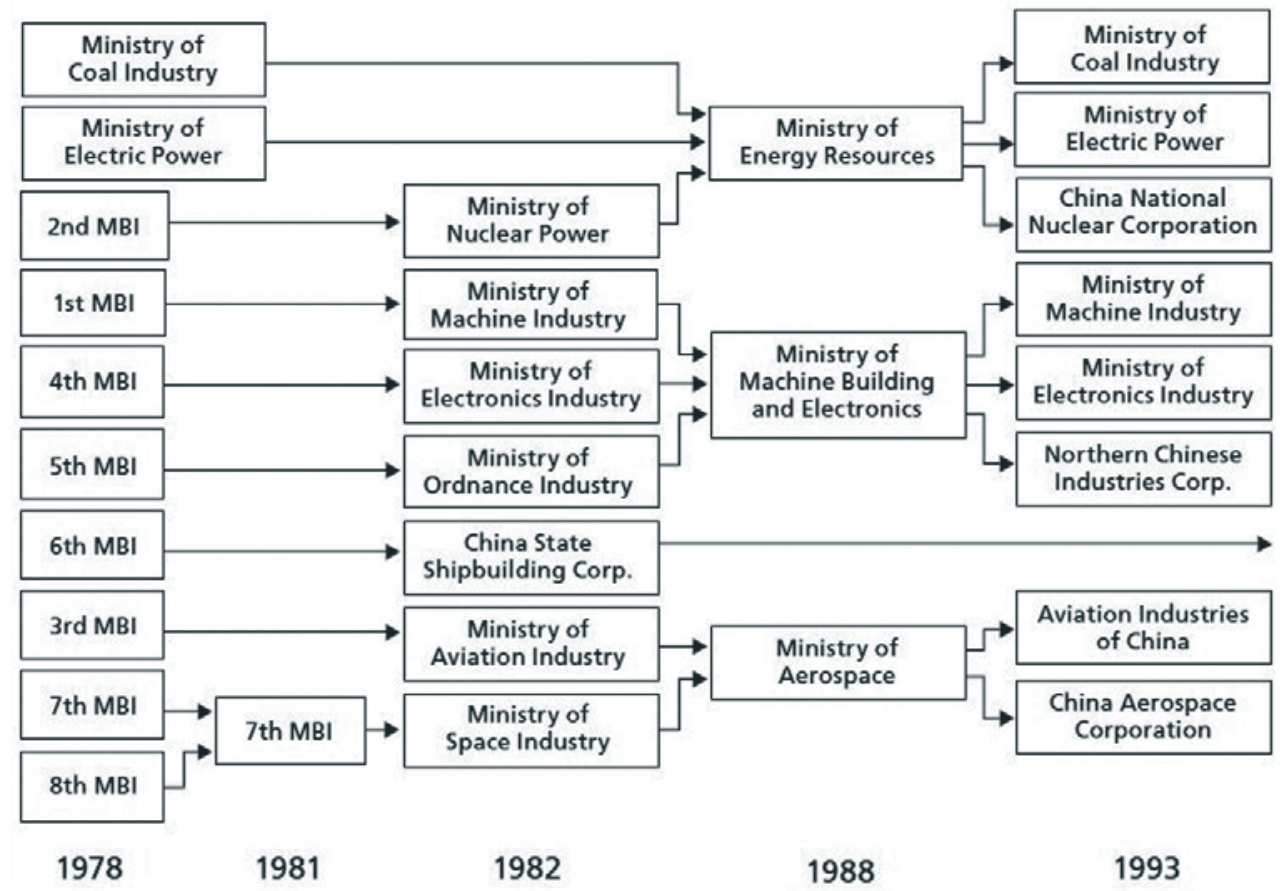

Fonte: (MEDEIROS et al, 2005, p. 15)

1990, e mais de US\$ 60 bilhóes/ano na década de 2000 (CUNHA, 2012, p. 56).

Esta nova orientação da Política Externa e da Política de Desenvolvimento chinesa também incluiu os investimentos militares, que gradativamente passaram a modernizar as capacidades convencionais do país, incluindo a Marinha. $\mathrm{Na}$ década de 1970, a China comissionou um submarino lançador de mísseis balísticos e navios-patrulha lançadores de mísseis cruzadores, ambos a partir de designs soviéticos adquiridos na década de 1950 (COLE, p. 2014, p. 53). Em 1979, a força de fuzileiros navais foi reativada, baseando-se também em navios construídos por estaleiros chineses como os destróieres da Classe Luda (Type-51, 3.670 toneladas) e as fragatas da Classe Jianghu (Type-053, de 2.000 toneladas) (COLE, 2014, p. 55). Cabe aqui ressaltar também a construção dos primeiros submarinos nucleares de ataque e de cerca de 60 submarinos convencionais (COLE, 2014, p. 13).
Em 1982, como demonstrado pela Figura 1 abaixo, o 60 Ministério de Construção de Máquinas (Sixth Ministry of Machine Building), até então responsável pelo setor naval, foi convertido na China State Shipbuilding Corporation (CSSC) administrando 153 organizações que abarcavam desde estaleiros para construção naval na área civil e militar até fábricas de siderurgia, produção de turbinas, institutos de pesquisa e universidades (COLLINS; GRUBB, 2009, p. 350). Além disso, a CSSC tinha autoridade para negociar a formação de joint ventures com empresas do exterior e também de firmar acordos de exportação por meio da recém-criada Companhia de Comércio de Construção Naval da China China Chipbuilding Trading Company (CSTC) (COLLINS;GRUBB, 2009, p. 350). Além da criação da CSSC, em 1982 houve a ascensão de Liu Huaqing ao comando da Marinha chinesa, tendo grande influência na estratégia de modernização naval do país até o fim de seu mandato na Comissão Militar Central, em 1997 (COLE, 2014, p. 56). 


\section{Aprofundamento das reformas e expansáo da indústria naval a partir dos anos 1990}

$\mathrm{Na}$ década de 1990, dois fatos conjunturais aumentaram a disposição da China em acelerar os investimentos em sua indústria naval civil e militar: a demonstração de força dos EUA na Guerra do Golfo de 1991 e a crise do estreito de Taiwan em 1996, na qual dois porta-aviōes norte-americanos foram posicionados na região em resposta a testes de mísseis chineses (O'ROURKE, 2016, p. 2). Nesse sentido, simultaneamente à expansão da indústria naval civil, pode-se destacar diversas modernizaçōes no campo militar: a construção local e comissionamento de (I) destróieres Classe Guangzhou (Type-52B), Classe Lanzhou (Type-52C) e Classe Kunming (Type-052D), (II) fragatas Type-053H2G (Jiangwei I), Type 053H3 (Jiangwei II), Type 054 (Jiangkai I), Type 054A (Jiangkai II), (3) corvetas da Classe Type 056 (Jiangdao) e Type 022 (Houbei), e (III) submarinos Classe Song (Type 039 ou 039G), Classe Jin (Type 094), Classe Shang (Type 093) e Classe Yuan (Type 039A) (MACHADO et al. 2016, p. 81-82).

Além disso, houve um vertiginoso aumento da construção naval chinesa para o mercado civil, tentando suprir um gap existente: em 1986, somente $18 \%$ da marinha mercante chinesa era constituída por navios produzidos no país (COLLINS; GRUBB, 2009, p. 351). Em 1992, a CSSC já tinha $80 \%$ de sua produção voltada ao mercado não-militar ${ }^{14}$, e cerca de $50 \%$ eram voltadas à exportação. A marinha mercante chinesa passou de 955 navios (6,5 milhóes de toneladas) em 1986 para 1.948 navios (13,9 milhóes de toneladas) em 1990 (COLLINS; GRUBB, 2009, p.

14. Desta forma, a maior parte dos estaleiros engajados na área civil já haviam atuado na construção de vasos de guerra; o contrário também é verdadeiro para a situação atual: os estaleiros envolvidos na construção de navios militares já tiveram experiência na construção de navios para o mercado civil (COLLINS e GRUBB, 2008, p. 5, 7-8).
352). Em 1993, a China já ocupava o terceiro lugar na construção naval mundial, ficando somente atrás de Japão e Coreia do Sul (COLLINS;GRUBB, 2009, p. 352). Em 2006, a China ultrapassou o Japão e passou a ocupar ao segundo lugar, com $35 \%$ do market share (WON, 2010, p. 8).

Em 1998, o 9 Encontro do National People's Congress (NPC) deu início a novas reformas instituicionais visando dinamizar o sistema de encomendas militares do Estado chinês e reestruturar as empresas do setor, que consistiam em cinco grandes corporaçóes: a China National Nuclear Corporation, a Aviation Industries of China, a Northern Chinese Industries Corporation (NORINCO) e a CSSC (MEDEIROS et al. 2005, p. 16). Neste sentido, em 1999 houve a criação da China Shipbuilding Industry Corporation (CSIC), nos mesmos moldes da CSSC (COLLINS;GRUBB, 2008, p. 5). A CSSC e a CSIC administram estaleiros, fábricas e institutos de pesquisa e desenvolvimento tanto na área civil quanto militar. Juntas, correspondiam a mais de $50 \%$ da construção naval do país (MEDEIROS et al. 2005, p. 115).

No final da década de 1970, a China a produção de navios para transporte comercial era estimada em um total de 100 mil toneladas por ano. Este valor cresceu de 135 mil em 1981 para 3,7 milhóes anuais em 2003, e seu market share passou de 3\% em 1993 para 13,8\% em 2003 (MEDEIROS et al. 2005, p. 124-125). Em 1996, a China tornou-se o terceiro maior construtor naval do mundo, perdendo somente para o Japão e para a Coreia do Sul, e em 2006 passou ao segundo lugar, com 35\% do market share (WON, 2010, p. 8). Em 2004, dos 8,5 milhōes de toneladas construídos, cerca de $70 \%$ foram realizados pela CSSC e pela CSIC (MEDEIROS et al. 2005, p. 125).

Além da construção de navios, as empresa chinesas passaram a desenvolver e produzir diver- 
sos equipamentos ligados ao setor marítimo (navipeças), inclusive motores e turbinas derivadas de projetos alemães, dinamarqueses, suíços, austríacos, noruegueses e de outros países (MEDEIROS et al. 2005, p. 132). O domínio dessas tecnologias permitiu à China avançar na produção de navios mais avançados, como corvetas, fragatas, destróiers e navios anfíbios.

Por fim, de maneira análoga ao desenvolvimento econômico nos EUA no início e na segunda metade do século XX, a China passou a criar um mercado de consumo e produção em massa por meio de empresas de diversos ramos. No setor de mineração, a Aliminum Corporation of China (Chalco) e a Baosteel; no setor de bens de consumo, telecomunicações e produtos eletrônicos, Huawei, Tool Command Language (TCL), Lenovo, Boe Technology, Galanz; alimentos e bebidas, como a Tsingtao, Cofco International; comércio e navegação (China Ocean Shipping Gropu, Sinocham Group; construção civil com a China State Construction and Engineering Company (CUNHA, 2012, p. 57). Entretanto, do ponto de vista do Produto Interno Bruto (PIB) chinês, é possível caracterizar o crescimento como sendo liderado pelos investimentos, que respondem por $44 \%$ (o consumo privado por $36,1 \%$, o consumo governamental por $13,5 \%$, e as exportaçóes líquidas por 8\%) (Asian Development Bank, 2009 apud CUNHA, 2012, p. 34).

Em relação à Pesquisa e Desenvolvimento $(\mathrm{P} \& \mathrm{D})$, os estaleiros chineses aproximaram-se cada vez mais de universidades e institutos de pesquisa, utilizando as parcerias internacionais para acelerar a absorção de conhecimento e o desenvolvimento de produtos nacionais de maior valor agregado. As alianças estratégicas, particularmente com Estados Unidos, URSS, Japão ${ }^{15}$, Coreia do

15. Como parceiros japoneses, pode-se citar: Mitsubishi Heavy Industries, Kawasaki Heavy Industries, IHI Heavy Industries,
Sul e países europeus ${ }^{16}$, auxiliaram na redução dos custos da modernização do complexo militar-industrial chinês. A cooperação técnica internacional chinesa incluía:

- designs conjuntos de navios produzidos por estaleiros nacionais e estrangeiros;

- intercâmbio de pessoal entre empresas; e

- acordos de transferência de tecnologia e produção conjunta (MEDEIROS et al. 2005, p. 131-132). Como exemplo, Collins e Grubb (2008, p. 7) citam a parceria da CSSC com a japonesa Mitsubishi Heavy Industries e com estaleiros britânicos para a modernização dos estaleiros Jiangnan e Dalian, inclusive obtendo licenças de produção de turbinas. No contexto do Auxílio Oficial para o Desenvolvimento (ODA), entre 1980 e 1989 o Japáo investiu cerca de US\$ 4 bilhóes na China, abarcando desde plantas industriais até obras de infraestrutura como rodovias, ferrovias, portos, sistemas de produção e transmissão de energia (SILVA, 2015).

No que tange à modernização de seus processos produtivos, pode-se citar a aquisição do software de design suíço TRIBON, especializado em desenvolvimento de navios (MEDEIROS et al. 2005, p. 130). Em relação à construção naval militar, na década de 1980 o país dedicou-se a modernizar navios soviéticos já adquiridos e, simultaneamente, a desenvolver navios próprios em sinergia às aquisiçôes de tecnologias do exterior (MEDEIROS et al. 2005, p. 124). Dentre elas, deve-se destacar a aquisiçẫo de turbinas a gás LM2500 e de torpedos antissubmarino, ambos dos EUA (COLE, 2014, p. 58).

Sumitomo Heavy Industries e Hitachi Zosen (MEDEIROS et al. 2005, p. 131).

16. Podem ser citados a aquisiçáo de torpedos italianos, mísseis cruzadores franceses e radares britânicos (COLE, 2014) 


\section{A trajetória da indústria naval civil e militar na Coreia do Sul}

No início dos anos 1960, o governo militar da Coreia do Sul, liderado por Park Chung-hee (19611979) iniciou uma série de planos econômicos de cinco anos para promover a produçáo industrial do país, incluindo a construção naval (SHIN; HASSINK, 2011, p. 12). O centro administrativo desta política era o Conselho de Planejamento Econômico (EPB, sigla em inglês), auxiliado pelos ministérios, particularmente o Ministério da Indústria e Comércio (MTI) e em estreita ligação aos Chaebols (EVANS, 1995, p. 52). Após nacionalizar e reorganizar o setor bancário, Hee inciou a política de promoção da Indústria Pesada e Química (HCI), com financiamento externo dos EUA e do Japão ${ }^{17}$ (SHIN; CICCANTELL, 2009, p. 174). Um exemplo foi o projeto da Usina Siderúrgica de Pohang Pohang Iron and Steel Company (POSCO), construído em 1968 com assistência técnica e financeira da empresa japonesa Nippon Steel (SHIN; CICCANTELL, 2009, p. 174). Além disso, em 1970 foi criada a Lei de Promoção à Indústria Siderúrgica, conferindo fontes estáveis de financiamento a juros baixos ao setor, que é essencial para a indústria naval (SHIN; CICCANTELL, 2009, p. 175).

Segundo relatório da Organização para a Cooperação e Desenvolvimento Econômico (2015, p. 6), a industrialização do país foi inciada na indústria leve intensiva em máo de obra nos anos 1950 e 1960, passando gradativamente à indústria pesada e à indústria de alta tecnologia nos anos 1970 e 1980, com alto valor agregado, associando Pesquisa e Desenvolvimento (P\&D) local à absorção de tecnologias do exterior. É nesta segunda fase (pós anos 1970) que se inseriu a indústria naval civil e militar.

17. A Coreia do Sul e o Japão normalizaram suas relaçóes em 1965, com o apoio dos Estados Unidos da América, particularmente devido à necessidade de aliados para a Guerra do Vietná.
Segundo Lee (2013, p. 145-146), este impulso industrial proporcionou a base econômica e tecnológica para capacitar o país a construir os complexos navios de guerra num momento posterior.

Assim, em 1973, a Hyundai Heavy Industry construiu o maior conjunto de estaleiros do mundo na Baía de Ulsan. Em 1974, entregou com sucesso sua primeira encomenda, uma Very Large Crude Carriers (VLCC) ${ }^{18}$ de 260.000 toneladas. (WON, 2010 , p. 7). A empresa começou a investir na construção de estaleiros com capacidade para navios de até 700.000 toneladas, passando inclusive a exportar grandes petroleiros (SHIN; HASSINK, 2011, p. 13-14). Além disso, em 1975 a Hyundai criou uma nova companhia especializada no reparo de navios, a Hyundai Mipo Shipbuilding Company (SHIN; HASSINK, 2011, p. 14). A Samsung não ficou para trás, e comprou a Woojin, empresa localizada em Geoje, na província de Gyeongnam, finalizando um grande estaleiro em 1977 naquela região (SHIN; HASSINK, 2011, p. 14). Simultaneamente, segundo Evans (1995, p. 110), na década de 1970, a Samsung, a Hyundai e a Daewoo tornaram-se produtores de manufaturados eletrônicos de estatura internacional.

A janela de oportunidade da Coreia do Sul foi o boom internacional da construção naval anterior às crises do petróleo (WON, 2010, p. 16). Além disso, as empresas sul-coreanas, com o auxílio do Estado, passaram a utilizar redes de importação de matérias-primas. A existência de fontes internas e externas baratas de matérias-primas facilitou a ascensão e a competitividade (escala produtiva) internacional tanto da indústria naval quanto da indústria siderúrgica no país. De fato, foi criada uma interdependência entre a POSCO e a indústria automobilística, naval, de construção civil, entre outras (SHIN; CICCANTELL, 2009, p. 176). Além

18. VLCC - Very Large Crude Carriers - Navios-tanque de altíssima tonelagem. 
disso, o governo sul-coreano estabeleceu que o transporte das importaçóes de petróleo seriam realizadas por navios mercantes nacionais recém-construídos pela Hyundai (SHIN; CICCANTELL, 2009, p. 181). A fundação do Banco de Exportação e Importação da Coreia do Sul (Korea Eximbank) em 1976, por sua vez, auxiliou na inserção internacional da economia do país.

Nos anos 1970, a Coreia do Sul promoveu a indústria de defesa como parte de sua estratégia de segurança nacional, particularmente devido à política de "burden-sharing" de Richard Nixon e às suas visitas à China como reação aos impasses da Guerra do Vietná. Segundo Lee (2013, p. 126), a retirada de 20 mil soldados norte-americanos da Coreia do Sul foi um fator essencial para a decisão de Park Chung-hee iniciar a construção de capacidades militares autônomas. Daí a criação, em 1974, pelo Estado Maior Conjunto, do Plano Nacional de Defesa (1974-1981) (também denominado Projeto Yulgok) e o estabelecimento da Agência para o Desenvolvimento da Defesa Agency for Defense Development (ADD) em 1970. A ADD seria responsável pelo desenvolvimento de diversos programas de defesa, incluindo o programa nuclear sul-coreano (LEE, 2013, p. 126). Além disso, em 1975, o presidente Park estabeleceu um imposto com a finalidade de angariar recursos para a indústria de defesa e servindo de suporte financeiro ao Projeto Yulgok (LEE, 2013, p. 114).

Assim, entre 1976 e 1977, a empresa sul-coreana Korea Tacoma International produziu, após transferência de tecnologia dos EUA, quatro unidades do PGM 581 Paek Ku, um pequeno navio patrulha com capacidade de lançar mísseis anti-navio com o objetivo de deter as provocaçóes da Coreia do Norte pelo mar (LEE, 2013, p. 73;112-113). Além disso, a Marinha da Coreia do Sul iniciou em 1975 esforços para a construçáo das fragatas da Classe Ulsan; os nove (9) navios foram finalizados entre 1980 e 1992, e sua fabricação foi conduzida pelas seguintes empresas: Hyundai, Daewoo, Busan e Tacoma. Em 1978, a Coreia do Sul produziu o seu primeiro míssil guiado, o NHK-I, também denominado Baekgom (Urso Branco), modelado a partir do mísseis norte-americanos Nike e Hércules (LEE, 2013, p. 121).

Em 1977, a administração Jimmy Carter (1977-1981) nos EUA estabeleceu mais um plano de retirada de tropas da Coreia do Sul, o que provocou protestos do presidente Park; em compensaçáo, os EUA prometeram um aporte de US\$ 2 bilhóes à Coreia do Sul, além de créditos suplementares e transferência de tecnologia para a indústria de defesa do país (LEE, 2013, p. 125). Assim, o Projeto Yulgok seria estendido em 1981 e em 1986, dando continuidade à construção naval militar, como a construção de corvetas (1981), navios caça-minas (1984), navios de suporte logístico e navios anfíbios (LEE, 2013, p. 114).

\section{Diversificação de parcerias e projeto de Mari- nha de Águas Azuis a partir dos anos 1990}

Entretanto, em 1986 os EUA rejeitaram a proposta sul-coreana de construção conjunta de submarinos convencionais (propulsão diesel-elétrica), o que levou o país a diversificar suas parcerias internacionais. A Coreia do Sul adquiriu, portanto, nove submarinos Type-209 da Alemanha, construídos pela Howaldtswerke-Deutsche Werft (HDW), e assinando um contrato de gradual transferência de tecnologia para empresa sul-coreana Daewoo Heavy Industries. A Daewoo seria responsável pela construção, na Coreia do Sul de mais oito (8) submarinos, ainda que muitos componentes fossem importados (LEE, 2013, p. 114). Desta forma, a partir da década de 1970 a Coreia do Sul foi progressivamente diversificando suas parcerias internacionais, ainda que mantendo os EUA como aliado prioritário. Como exemplos, podemos citar a Itá- 
lia (canhóes Oto Melara 40L 70 e $76 \mathrm{~mm}$ para as fragatas Ulsan), Países Baixos (sistemas de sensores DA-05 de rastramento do ar e radares de controle de fogo WM-20), França (mísseis anti-navio MM38 Exocet e motores a diesel PA-6), e a Alemanha (submarinos Type 209, motores Unidade Máxima de Transmissão (MTU) para submarinos e corvetas, e torpedos do modelo SUT, Surface and Underwater Target, guiados por fio) (LEE, 2013, p. 128-129).

Os navios de guerra de superfície construídos pela Coreia do Sul detinham grande porcentagem de conteúdo local, mas contaram com grande aporte tecnológico externo; um exemplo são os destróiers da Classe Gwanggaeto the Great (série KDX-I, de 3.000 toneladas) e os destróiers da Classe Sejong the Great (série KDX-III, de 7.600 toneladas). Na série KDX-I, a Daewoo construiu os navios, mas componentes como turbinas a diesel, sistemas de combate e comando e controle foram importados. Na série KDX-III, os técnicos da Hyundai consultaram diretamente a Marinha dos EUA e a Lockheed Martin desde as fases de design do navio até a construção do Sistema AEGIS de combate (LEE, 2013, p. 145).

$\mathrm{Na}$ década de 1990, a valorização do yen japonês e o aumento dos custos da máo de obra prejudicaram os estaleiros no Japáo; por outro lado, devido à crise financeira asiática de 1997, houve uma desvalorização do won sul-coreano frente ao dólar, permitindo uma redução do preço das embarcações (SHIN; CICCANTELL, 2009, p. 180). Como resultado, a Coreia do Sul passou de 25\% para 36\% do market share da indústria de construção naval do mundo (FIRST MARINE LIMITED INTERNATIONAL, 2003 apud WON, 2010 , p. 16). O acelerado crescimento econômico chinês nas décadas de 1990 e 2000 aumentou a demanda por navios-contêiners, navios de transporte de gás natural liquefeito (LNG) de tonelagem cada vez maior.
Desta forma, houve a criação de novas instituiçôes para aumentar a competitividade das empresas da Coreia do Sul. Em 1992 foi estabelecido o K-Sure, uma agência estatal de crédito à exportação que, junto ao Korea Eximbank, constituíram os instrumentos do Estado para o financiamento das exportações sul-coreanas, inclusive da indústria naval. Assim, as vendas e os lucros dos estaleiros sul-coreanos aumentaram drasticamente, levando a altos investimentos para suprir a demanda global (WON, 2010, p. 7). Em 1997 foi criado o Instituto Coreano de Estratégia Marítima (KIMS), responsável por promover pesquisa e recomendaçóes para a estratégia marítima do país (LEE, 2013, p. 137).

$\mathrm{Na}$ esteira desta expansão econômica, o presidente Roh Tae-woo (1988-1993) iniciou as tratativas com os EUA em relação à transferência do Controle Operacional (OPCON) das Forças Armadas da Coreia do Sul para o Estado sul-coreano, processo que seria iniciado em 1992 (LEE, 2013, p. 115116). A estratégia de política externa conhecida como Nordpolitik de Tae-woo foi caracterizada pela normalização das relaçóes com a China em 1992 (LEE, 2013, p. 101). Este aumento de autonomia na política externa sul-coreana esteve em sintonia à percepção do Secretário de Defesa dos EUA Richard Cheney de que seus aliados asiáticos deveriam assumir maiores responsabilidades pela sua defesa, enquanto os norte-americanos reduziriam sua presença na região (LEE, 2013, p. 108-109).

Foi nesse contexto político que, em 1995, a Coreia do Sul traçou o plano de constituir uma Marinha de Águas Azuis ${ }^{19}$ (Blue Water Navy BWN), visando a construção de navios de maior porte e de maior capacidade de combate, como os seis destróiers da série KDX-II (4.500 toneladas),

19. Marinha de Águas Azuis - Trata-se de uma Marinha capaz de operar longe de seu litoral, nos mares e oceanos. Atualmente, somente os EUA detém esta capacidade de projetar poder em qualquer lugar do mundo. Trata-se de obter, nas palavras de Alfred Mahan, o Comando do Mar (FONT; RUFÍ, 2006, p. 67; COSTA, 2008, p. 68-69). 
comissionados a partir de 2003, e a série KDX-III (7.500 toneladas), comissionados a partir de 2008. Assim, o Plano de Defesa da Coreia do Sul 20012005 já incorporou a construção dos destróiers AEGIS (KDX-III), sendo a primeira unidade comissionada em 2008 (ROK Sejong the Great, DDG 991) (LEE, 2013, p. 99).

Em relação à indústria naval militar, as sul-coreanas Hyundai, Samsung e Daewoo cresceram como exportadores, levando a Coreia do Sul a passar de US\$ 250 milhóes em 2006 para US\$ 2,6 bilhóes em 2013 nesse ramo (MUNDY, 2013). A Hyundai produz tanto submarinos, destróieres e fragatas, quanto navios-tanque de altíssima tonelagem (mais de 250.000 toneladas), graneleiros, petroleiros, supercargueiros e navios porta contêineres (VLADIMIR, 2012). A Daewoo, por exemplo, fechou contratos de venda para a Tailândia de uma fragata no valor de US\$500 milhóes, de três submarinos por US\$ 1,1 bilhão, e para o Reino Unido de quatro navios-tanque para a Marinha Britânica (MUNDY, 2013). Além disso, está construindo submarinos para a Indonésia e também operando transferência de tecnologia para a mão de obra especializada daquele país.

\section{Pesquisa e Desenvolvimento (P\&D)}

A construção naval é um setor intensivo tanto em mão de obra quanto em tecnologia. Desta forma, tanto o Estado quando as empresas da Coreia do Sul criaram instituições para auxiliar na capacidade produtiva e tenológica das empresas nacionais, particularmente por meio de Pesquisa e Desenvolvimento (P\&D) e de geração de mão-de-obra qualificada. Daí a criação do Instituto Coreano de Ciência e Tecnologia Oceânicas (KIOST) em 1973, do Intituto de Pesquisa de Pequenos e Médios Construtores Navais (RIMS) em 1996, e do Instituto Coreano de Pesquisa em Equipamentos Marinhos (KOMERI) em 2001.
No setor naval militar os investimentos em P\&D são recentes. Em 2014, a Daweoo Shipbuilding and Marine Engineering (DSME) abriu um centro especializado em navios de guerra, o primeiro do país. O número de pessoas empregadas em P\&D no setor naval aumento de $1.311 \mathrm{em} 1996$ para 2.360 em 2004 (SHIN; CICCANTELL, 2009, p. 181-182). Atualmente, há uma preocupação do setor de uma possível escassez de mão de obra jovem devido à tendência de envelhecimento da população sul-coreana.

Segundo Evans (1995, p. 143), diferentemente dos casos do Brasil e da Índia, os atores privados estiveram desde cedo envolvidos com as atividades de $\mathrm{P} \& \mathrm{D}$, integrando, portanto, inovação e difusão tecnológica (capacidade produtiva). Os Chaebols sul-coreanos investem em inovação tecnológica, buscando vantagens competitivas frente a outros países, como novas formas de economia de combustível nas embarcaçóes, investimentos em novas áreas como na extração de combustíveis off-shore, como petróleo Unidade flutuante de produção, armazenamento e transferência (FPSO) e gás natural Floating liquefied natural gas (FLNG), e também em novas técnicas de produção: fabricação de navios no interior do continente, montagem por meio de blocos gigantes (giga-blocks) e barragens submersas (OCDE, 2015, p. 18).

Além disso, a indústria de construção naval aproxima-se cada vez mais das universidades. Por exemplo, a Samsung estabeleceu uma parceria com a Universidade Nacional de Pusan e o Departamento de Engenharia Naval para o lançamento de cursos de capacitação. Em 2012, a DSME criou a DSME Heavy Industries Academy, visando alunos recém formados do ensino médio que queiram especializar-se nesta área, garantindo acesso a empregos na DSME (OCDE, 2015, p. 21). Atualmente, segundo a $\operatorname{OCDE}(2015$, p. 32) existem na Coreia do Sul 21 universidades, 18 faculdades e 16 programas de 
pós-graduaçáo relacionados à Engenharia de Naval. O foco atual do governo sul-coreano é a indústria Offshore, e há iniciativas de criação de institutos voltados a esse setor, particularmente coordenadas pela Associação Coreana de Indústria Naval e Offshore (KOSHIPA), com suporte do Ministério da Indústria, Comércio e Energia (MOTIE) da Coreia do Sul e em cooperação com os três grandes Chaebols da construção naval: Hyundai, Samsung e DSME (Daewoo) (OCDE, 2015, p. 32).

\section{Consideraçóes finais e balanço dos estudos de caso}

Em vias de conclusão, pode-se afirmar que, guardadas as devidas proporçôes e contextos históricos, China e Coreia do Sul trazem importantes indicadores acerca das relaçôes entre a Base Industrial de Defesa e os modelos de desenvolvimento econômico existentes. De forma resumida, pode-se elencar as seguintes características comuns da evolução da indústria naval civil e militar nesses países:

- importante papel do Estado como fomentador da economia e da Base Industrial de Defesa,

(2) criação de Arranjos Institucionais capazes de atender às demandas políticas e econômicas do Estado e das empresas frente às demais potências do Sistema Internacional; e

- parcerias internacionais de geometria variável visando ganhos tecnológicos e escala produtiva.

$\mathrm{Na}$ China, as reformas institucionais acompanharam as demandas políticas, econômicas e militares do país na regiáo do Leste Asiático, mas também no âmbito do Sistema Internacional, particularmente barganhando com EUA, URSS, Japão, Coreia do Sul e países da Europa Ocidental. A partir da diversificação das parcerias internacionais na década de 1970, a China criou um sistema híbrido próprio a partir da estrutura do Estado. A indústria naval civil e militar, em sinergia com os demais setores, constituiu:
- o núcleo da economia de escala para a exportação de produtos industrializados, e

- um cluster de modernização tecnológica e de sinergia entre diversos ramos industriais do país, das matérias-primas até a microeletrônica.

A Coreia do Sul, mesmo com o benefício das parcerias externas no contexto da Guerra Fria, particularmente o apoio norte-americano, europeu e as alianças regionais, expandiu sua indústria naval como parte do processo de construção da soberania do país após a Guerra Civil de 1950-1953. O PIB per capta da Coreia do Sul aumentou de US\$ $81 \mathrm{em}$ 1960 para US\$ 1.510 em 1980, chegando a US\$ 18.374 em 2006 (SHIN; HASSINK, 2011, p. 11). A proporção da indústria no PIB cresceu de 16,2\% em 1970 para 24,7\% em 2006, e a geração de emprego de 9\% para 28\% entre 1970 e 1990 (SHIN; HASSINK, 2011, p. 11). Para isso, foi essencial a aliança entre o Estado sul-coreano e os Chaebols, que permitiram a formação de clusters ${ }^{20}$ de sinergia entre a indústria de bens de consumo, a indústria pesada e a indústria de defesa. Esta relação se deu por meio da criação de mecanismos de financiamento, proteção da indústria nascente, criação de infraestrutura e de instituições de ensino e P\&D capazes de gerar mão de obra qualificada. Assim, a indústria naval sul-coreana passou a formar uma parte de um grande cluster marítimo, integrando desde a indústria do aço até os equipamentos eletrônicos.

Pode-se dizer que o modelo de desenvolvimento empresarial de negócios e serviços chinês e sul-coreano assemelha-se àquele formatado nos EUA a partir da segunda metade do século XIX, carac-

20. Cluster - Segundo Porter (2000, p. 16 apud SHIN; HASSINK, 2011, p. 5), um cluster é um grupo de companhias e instituiçôes interconectadas por uma determinada atividade, formando uma cadeia de valor, escala, inovação e compartilhamento de conhecimento. Os clusters são áreas de geraçáo de novos espaços industriais de janelas de oportunidade para novos negócios e serviços. O objetivo é a geração de spin-offs, ou seja, cadeias produtivas de subcontratação que multipliquem a geração de emprego, renda e, ao mesmo tempo, aumentem o nível tecnológico dos produtos produzidos e exportados. 
terizado por Alfred Chandler Júnior (1994) como "capitalismo gerencial competitivo". Diferentemente do modelo alemão, cujas empresas priorizaram a integraçáo horizontal (cada empresa possuía um monopólio em um setor específico da economia), EUA, China e Coreia do Sul buscaram integração vertical de empresas, formando conglomerados que competiriam entre si domesticamente e no exterior em diversas áreas da economia, gerando ganhos de escala e modernização tecnológica simultaneamente. Pode-se dizer, com maior precisão, que a China também adotou algumas características de integração horizontal, do "capitalismo gerencial cooperativo" alemão, principalmente quando da formação inicial de seu Complexo Militar-Industrial. Os Chaebols sul-coreanos, por outro lado, desde o início assemelharam-se ao modelo estadunidense.

Em termos geopolíticos e geoeconômicos, China e Coreia do Sul vivem situaçóes semelhantes. Ainda que em escalas populacionais e econômicas distintas, ambos países têm o transporte marítimo como núcleo de seus modelos de desenvolvimento, principalmente no que tange ao comércio e à Segurança e Defesa. As linhas marítimas de comunicação Sea Lines of Communication (SLOCs) ligam o Oceano Pacífico ao Oceano Índico (acesso ao Sul da Ásia e ao Oriente Médio) e ao Oceano Atlântico (relações com os EUA, América do Sul e Europa Ocidental). À medida em que aumentam as tensóes político-militares no Mar do Sul da China, e em que intensificam-se a formaçấo de blocos econômicos regionais e interregionais - o Trans-Pacific Partnership (TPP ${ }^{21}$ ), o Transatlantic Trade and Investment Partnership (TTIP ${ }^{22}$ ), o Asian Infrastruc-

21. Trans-Pacific Partnership (TPP) - Acordo de livre comércio e de regulação econômica assinado em 7 de outubro de 2015. Abarca os seguintes países: Chile, Brunei, Nova Zelândia, Cingapura, Austrália, Canadá, Japão, Malásia, México, Peru, EUA e Vietnâ. Apesar da assinatura do acordo, a ratificação interna dos países ainda não ocorreu.

22. Transatlantic Trade and Investment Partnership (TTIP) Proposta de acordo econômico entre Estados Unidos e União ture Investment Bank (AIIB ${ }^{23}$ ) e o Regional Comprehensive Economic Partnership (RCEP $\left.{ }^{24}\right)$, entre outros -, cresce a possibilidade de disputas entre os países da regiáo do leste e sudeste asiático.

Nos últimos anos, a indústria naval mundial passou por uma fase de retração: de 2009 a 2013 o número total de embarcações encomendadas caíram em 50\%. Em 2014 e em 2015 as três maiores empresas sul-coreanas terminaram o ano com déficits acumulados e açôes em queda (PARK; BURGOS, 2016). Os estaleiros chineses também tiveram suas encomendas reduzidas em mais de 40\% em 2014 e em 2015 (CHINA DAILY, 2016; CHINA'S..., 2016). Isto é derivado também da queda no comércio exterior chinês: em 2015, as exportações do país caíram 1,3\% e as importaçóes foram reduzidas em 13,2\% (EINHORN, 2016)

Este processo se deve a diversos fatores. Primeiramente, a queda do preço do petróleo a partir do segundo semestre de 2014 - de mais de US\$100,00 para US\$ 30,00 em dezembro de 2015 - levou a uma queda dos investimentos e da captaçáo de recursos pelas empresas petrolíferas. Por outro lado, o menor preço desta commodity ampliou a capacidade produtiva das indústrias que tem o petróleo como insumo, levando a um aumento excessivo da oferta em relação à demanda global. Em segundo lugar, há uma retração da demanda externa global, não somente na China mas também na Europa e nos EUA.

Em termos sistêmicos, pode-se dizer que chegou-se a um limite da expansão da $3^{a}$ Revolução Industrial baseada na microeletrônica, ou seja, há a necessidade de criação de novas cadeias produtivas

Europeia exposto em março de 2014.

23. Asian Infrastructure Investment Bank (AIIB) - Banco Asiático de Investimento em Infraestrutura proposto pela China e formado em 24 de outubro de 2014.

24. Regional Comprehensive Economic Partnership (RCEP) - Proposta de acordo econômico entre China, Japão, Coreia do Sul, Austrália, Nova Zelândia e os países da ASEAN. As negociaçōes foram iniciadas em novembro de 2012, e a décima rodada ocorreu de 12 a 16 de outubro de 2015 . 
e de valor para dar sustentação à demanda no longo prazo, o que passa pelos investimentos em inovação tecnológica e ampliação do mercado consumidor. A indústria naval, como demonstrado nos estudos de caso, foi um elemento importante para o modelo de desenvolvimento na China e da Coreia do Sul, auxiliando na entronização de tecnologias produtivas da $3^{a}$ Revolução Industrial, baseada nas redes de computadores e de comunicação. Neste sentido, a indústria de defesa - particularmente a modernização naval - tem sido utilizada pelos países para responder às duas demandas citadas:

- o aumento das tensóes militares na regiáo e

- os investimentos tecnológicos necessários para superar os atuais limites de seus modelos de desenvolvimento, pela modernização produtiva e pela abertura de novos mercados.

\section{Referências}

AGÊNCIA BRASILEIRA DE DESENVOLVIMENTO INDUSTRIAL. Panorama da base industrial de defesa: segmento naval. Brasília: ABDI, 2013.

CHANDLER JÚNIOR, Alfred. Scale and scope: the dynamics of industrial capitalism. Massachusetts: Harvard University Press, 1994.

CHINA'S shipbuilders strive to navigate economic cold. [S.1.]: China Daily, 16 fev. 2016. Disponível em: <http://www. chinadaily.com.cn/business/2016-02/16/content 23505506. htm>. Acesso em: 16 fev. 2016.

CHINA'S shipbuilding slumps,[S.I.]: IOL, 18 jan. 2016. Disponível em: <http://www.iol.co.za/business/international/chinas-shipbuilding-slumps-1972455>. Acesso em: 16 fev. 2016.

COLE, Bernard D. More red than expert: China sea power during the cold war. In: ERICKSON, Andrew S.; GOLDSTEIN, Lyle J.; LORD, Carnes. China goes to sea: maritime transformation in comparative historical perspective. Annapolis: Naval Institute Press, 2009, p. 320-340.

COLE, Bernard D. The history of the twenty-first-century Chinese navy. Naval War College Review, v. 67, n. 3, Summer 2014. COLLINS, Gabe. China's shipbuilding industry development: a boost for naval ship production? Study of innovation and technology in China, Policy Brief, n. 7, Sept. 2010.
COLLINS, Gabriel. China's Shipbuilding Industry Development: A Boost for Naval Ship Production? Study of Innovation and Technology in China, Policy Brief n ${ }^{\circ}$ 7, september 2010. Disponível em: <https://escholarship.org/uc/item/7264x5k8>.

COLLINS, Gabriel; GRUBB, Michael C. A comprehensive survey of China's dynamic shipbuilding industry: commercial development and strategic implications. Rhode Island: $\mathrm{Na}$ val War College, 2008.

COLLINS, Gabriel; GRUBB, Michael C. Strong foundation: contemporary chinese Shipbuilding Prowess. In: ERICKSON, Andrew S.; GOLDSTEIN, Lyle J.; LORD, Carnes. China goes to sea: maritime transformation in comparative historical perspective. Annapolis: Naval Institute Press, 2009.

CONTI, Fátima. A história do computador e da internet. Belém: Universidade Federal do Pará, jun. 2006. Disponível em: <http://www.ufpa.br/dicas/net1/int-h196.htm>. Acesso em: 16 nov. 2014.

CUNHA, André M. China: desempenho econômico e comércio internacional. In: DATHEIN, Ricardo. (Org.). Parceiros estratégicos para a inserçáo internacional do Brasil: Ásia, África e Europa. Porto Alegre: Editora da UFRGS, 2012.

DORES, Priscila Branquinho das; LAGE, Elisa Salomão; PROCESSI, Lucas Duarte. A retomada da indústria naval brasileira. Rio de Janeiro: BNDES, 2012. Disponível em: $<$ http://www.bndes.gov.br/SiteBNDES/export/sites/default/ bndes_pt/Galerias/Arquivos/conhecimento/livro60anos_perspectivas_setoriais/Setorial60anos_VOL1ConstrucaoNaval. pdf $>$. Acesso em: 16 nov. 2014.

DUMAS, Roberto Dumas. Economia chinesa: transformaçóes, rumos e necessidades de rebalanceamento do modelo econômico da China. São Paulo: Saint Paul, 2014.

EINHORN, Bruce. The shipping industry is suffering from China's trade slowdown: so many boats, so little cargo as Chinese exports and imports drop. [S.1.]: Bloomberg Business, 11 fev. 2016. Disponível em: <http://www.bloomberg.com/news/ articles/2016-02-11/shipping-industry-suffering-from-china-s-trade-slowdown>. Acesso em: 17 fev 2016.

ERICKSON, Andrew S.; GOLDSTEIN, Lyle J.; LORD, Carnes. China goes to sea: maritime transformation in comparative historical perspective. Annapolis: Naval Institute Press, 2009.

EVANS, Peter. Embedded autonomy: states e industrial transformation. New Jersey: Princeton University Press, 1995.

FAVARIN, Julio V. R. et al. Competitividade da indústria naval brasileira. In: CONGRESSO NACIONAL DE TRANSPORTE AQUAVIÁRIO, CONSTRUÇÃO NAVAL E OFFSHORE, 23., 2010, Rio de Janeiro. Anais... Rio de Janeiro, 2010. Disponível em: http://www.saviesa.org.br/mapeamento/biblioteca/Competitividade\%20da\%20Industria\%20Naval\%20 Brasileira.pdf>. Acesso em: 16 nov. 2014.

FEDDERSEN, Gustavo Henrique et al.; A interação estratégica China-Estados Unidos envolvendo Taiwan: Elementos 
Para Uma Análise Atual. Revista Conjuntura Austral. v. 7, n. 33-34. 2016.

FIANI, Ronaldo. Arranjos Institucionais e Desenvolvimento: O papel da coordenação em estruturas híbridas. In: GOMIDE, A. A.; PIRES, Roberto (org.). Capacidades Estatais e Democracia: Arranjos institucionais de políticas públicas. Brasília: Ipea, 2014.

FURTADO, Celso. A pré-revoluçáo brasileira. Rio de Janeiro: Editora Fundo de Cultura, 1962.

FURTADO, Celso. Desenvolvimento e subdesenvolvimento. Rio de Janeiro: Contraponto, 2009.

FURTADO, Celso. Formação econômica do Brasil. São Paulo: Companhia das Letras, 2007.

GILPIN, Jean M. Global political economy: understanding the international economic order. United Kingdom: Princeton University Press, 2001.

GOMIDE, Alexandre de Ávila; PIRES, Roberto Rocha. Capacidades estatais e democracia: a abordagem dos arranjos institucionais para análise de políticas públicas. In: GOMIDE, Alexandre de Ávila; PIRES, Roberto Rocha C. (Ed.). Capacidades estatais e democracia: arranjos institucionais de políticas públicas. Brasília: IPEA, 2014.

INTERNATIONAL INSTITUTE FOR STRATEGIC STUDIES. The military balance: the annual assessment of global military capabilities and defence economics. London: IISS, 2016.

LEE, Sangyup. Ships, security, and symbols: a constructivist explanation of south korea's naval build-up. 2013. 385 f. Tese (Doutorado). The State University of New Jersey, New Jersey, 2013.

MACHADO, Luís Rodrigo et al. Elementos da modernização naval chinesa: a política de defesa e a doutrina naval sob a luz de seus desafios estratégicos. Revista Conjuntura Austral, v. 7, n. 33-34. 2016.

MARTINS, José Miguel Quedi; MAGNO, Bruno. A Longa Marcha da Revoluçáo Chinesa (1921-1949). In: VISENTINI, Paulo G. F.; PEREIRA, Analúcia D.; MARTINS, José M.; RIBEIRO, L. D.;GROHMANN, L.G. Revoluçóes e Regimes marxistas: Rupturas, experiências e impacto internacional. Porto Alegre: Leitura XXI, 2013. pp. 92-113.

MARTINS, José Miguel Quedi. Digitalizaçáo e guerra local como fatores do equilíbrio internacional. 2008. $327 \mathrm{f}$. Tese (Doutorado em Ciência Política) - Universidade Federal do Rio Grande do Sul, Instituto de Filosofia e Ciências Humanas, Porto Alegre, 2008.

MEDEIROS, Evan S. et al. A new direction for China's defense industry. Santa Monica: RAND Corporation, 2005.

MOTORA, Seizo. A hundred years of shipbuilding in Japan. Journal of Marine Science and Technology, 1997. p. 197-212. MUNDY, Simon. South Korea aims to become defence powerhouse. South Korea: Financial Times, 6 nov. 2013. Disponível em: < https://next.ft.com/content/66a9a33a-42ea-11e3-8350-00144feabdc0 >. Acesso em: 05 jul 2015.
MEARSHEIMER, John. The tragedy of great power politics. New York: W. W. Norton, 2001.

MURILLO, David; SUNG, Yun-dal. Understanding korean capitalism: chaebols and their corporate governance. [S.1.]: ESADEgeo - Center for Global Economy and Geopolitics. Position Paper 33, 2013.

OLIVEIRA, Lucas K. Energia como recurso de poder na política internacional: geopolítica, estratégia e o papel do centro de decisão energética. 2012. 400 f. Tese (Doutorado em Ciência Política) - Universidade Federal do Rio Grande do Sul. Programa de Pós-Graduação em Ciência Política, Porto Alegre, 2012. Disponível em: <http://www.lume.ufrgs.br/handle/10183/76222>. Acesso em: 28 nov. 2014.

ORGANIZAÇÃO PARA A COOPERAÇĀO E DESENVOLVIMENTO ECONÔMICO. Peer review of the korean shipbuilding industry and related government policies. France: OCDE, 2015. Disponível em: <http://www.oecd.org/sti/ind/ peerreviewofthekoreanshipbuildingindustryandrelatedgovernmentpolicies.htm>. Acesso em: 07 jul. 2015.

O'ROURKE, Ronald. China naval modernization: implications for US navy capabilities: background and issues for congress. [S.1]: Congressional Research Service. 2016 Disponível em: <https://www.fas.org/sgp/crs/row/RL33153.pdf>. Acesso em: 07 ago. 2016.

PARK, Kyunghee; BURGES, Jonathan. Blame it on oil: 2016 unhappy new year for asian shipyards. [S.l.]: Bloomberg Business, 3 jan. 2016. Disponível em: <http://www.bloomberg. com/news/articles/2016-01-03/blame-it-on-oil-2016-an-unhappy-new-year-for-asian-shipbuilders>. Acesso em: 16 fev. 2016.

PORTER, Michael E. Competition in global industries. Cambridge: Harvard Business School Press, 1986.

ROBERTS, J. A. G. História da China. Lisboa: Texto e Grafia, 2012.

SILVA, Athos Munhoz Moreira da. A ascensáo da China e os seus impactos para o leste asiático. 2015. 185 f. Dissertação (Mestrado) - Universidade Federal do Rio Grande do Sul, Programa de Pós-Graduação em Estudos Estratégicos Internacionais. Porto Alegre: UFRGS, 2015.

SHIN, Dong-Ho.; HASSINK, Robert. Cluster life cicles: the case of the shipbuilding industry cluster in South Korea. Regional Studies. v. 45, n.10, 2011.

SHIN, Kyoung-ho.; CICCANTELL, Paul S. The steel and shipbuilding industries of south Korea: rising east Asia and globalization. American Sociological Association, v. 15, n. 2, p. 167-192. 2009.

SINDICATO NACIONAL DA INDÚSTRIA DA CONSTRUÇÃO E REPARAÇÃO NAVAL E OFFSHORE. Cenário da construção naval: $1^{\circ}$ semestre de 2015. Rio de Janeiro: SINAVAL, 2015. Disponível em: <http://docplayer.com.br/ 11357983-Sinaval-cenario-da-construcao-naval-1o-semestre-de-2015.html>. Acesso em: 15 fev. 2016. 
SINDICATO NACIONAL DA INDÚSTRIA DA CONS-

TRUÇÃO E REPARAÇÃO NAVAL E OFFSHORE. Estaleiros da Coréia do Sul retomam liderança em 2014. Rio de Janeiro: SINAVAL, 20 fev. 2015. Disponível em: <http://sinaval.org.br/2015/02/estaleiros-da-coreia-do-sul-retomam-lideranca-em-2014/>. Acesso em: 07 jul 2015.

SHIPBUILDING Statistics [S.l]: The Shipbuilders' Association of Japan, Mar. 2015. Disponível em: <http://www.sajn.or. jp/e/statistics/Shipbuilding_Statistics_Mar2015e.pdf>. Acesso em: 15 fev. 2016.

VLADIMIR, Nikola. South Korean Shipyard Hyundai Heavy Industries. Brodo Gradnja. 2012. Disponível em:

<https://bib.irb.hr/datoteka/575847.South Korean shipyard_Hyundai Heavy Industries.pdf $>$. Acesso em: 08 ago. 2016.

VISENTINI, Paulo G. Fagundes et al.; Revoluçôes e regimes marxistas: rupturas, experiências e impacto internacional. Porto Alegre: Leitura XXI, 2013.

WON, Duck Hee. A study of korean shipbuilders' strategy for sustainable growth. 2010. 96 f. (Master's degree) Studies - Massachusetts Institute of Technology, Massachusetts. 2010. 